\title{
O IDEOGRAMA E A POESIA CONCRETA BRASILEIRA: UM ESTUDO DE DOIS POEMAS DE HAROLDO DE CAMPOS
}

Karoline Biscardi Santos - FALE/UFMG

A importância do estrato óptico das obras literárias foi, durante muito tempo, subestimada. De acordo com Maria Luiza Ramos (1972, p. 60-61), o filósofo Roman Ingarden, por exemplo, considera-o "irrelevante" e afirma que o material escrito não tem outra função senão a de indicar os fonemas a serem realizados pelo leitor. No entanto, a partir da publicação do poema Un coup de dés por Mallarmé, em 1897, iniciou-se uma busca pela exploração da espacialidade e das inovações tipográficas aplicadas à poesia - busca esta que influenciou, entre outros movimentos literários, o Concretismo, considerado por Inês Oseki-Dépré “o primeiro movimento de vanguarda brasileiro de repercussão internacional" (2000, p. 7).

Partindo de pressupostos teóricos contidos nas coletâneas de artigos Teoria da poesia concreta e Ideograma: Lógica-Poesia-Linguagem, organizadas por Augusto e Haroldo de Campos, respectivamente, tencionamos percorrer brevemente as características do método ideogrâmico conforme descrito por Ernest Fenollosa. Em seguida, analisaremos dois poemas de Haroldo de Campos - "LITAIPOEMA: TRANSA CHIM" e "via chuang-tsé 1" - e discutiremos efeitos visuais e nuances de sentido resultantes desta modalidade de composição para os poemas mencionados.

O grupo Noigandres, fundado por Décio Pignatari e os irmãos Augusto e Haroldo de Campos em 1952, propõe, em Teoria da poesia concreta, publicado pela primeira vez em 1965, a abolição do verso, a apresentação "verbivocovisual” do poema - isto é, segundo os valores gráficos e fônicos relacionais das palavras - e o rompimento da sintaxe lógico-discursiva em prol de uma conexão paronomástica entre termos utilizados no poema. Melo e Castro (1993, p. 229) afirma que, entre as inovações propostas pelo concretismo, está a possibilidade de se "escrever e ler sem ser ao longo de um eixo (da esquerda para a direita)". Através da incorporação da 
visualidade ao poema, a comunicação de estruturas substituiria a comunicação de conteúdos verbais e de interpretações do mundo objetivo. Décio Pignatari chama essa revolução no fazer poético de "ataque lúcido contra o jargão lírico e a peste metafórico-liriferante que assola a poesia nacional e mundial" (1975, p. 75), atribuindo ao poeta pernambucano João Cabral de Melo Neto o pioneirismo nessa investida. Para Haroldo de Campos (1975, p. 105), o poema concreto “não é intérprete de objetos, mas sim um objeto por direito próprio".

Ainda em Teoria da poesia concreta, Pignatari e os irmãos Campos reconhecem a influência de Ezra Pound e seu "método ideogrâmico de compor" sobre a poesia concreta. Pound teria sido o fundador da teoria do ideograma aplicado à poesia, a partir da publicação, em 1919, dos escritos de Ernest Fenollosa a respeito da utilização poética dos caracteres chineses, ou ideogramas. A importância do ideograma enquanto instrumento para a composição poética concretista deriva de sua consonância com propostas do movimento, tais como a ênfase na visualidade significativa, a busca pela comunicação de estruturas-conteúdos e o apreço pelas relações entre as formas.

Em seu ensaio "Os caracteres da escrita chinesa como instrumento para a poesia", Fenollosa aproxima os ideogramas dos processos da natureza, afirmando que os mesmos obedecem “à sugestão natural”. Além disso, compara a "palavra” chinesa à palavra ocidental: "Lendo o chinês, não temos a impressão de estar fazendo malabarismo com fichas mentais, e sim de observar as coisas enquanto elas vão tecendo seu próprio destino" (2000, p. 114-115).

De fato, alguns ideogramas guardam diferenças essenciais em relação às letras e aos signos verbais ocidentais. Para diferenciar letras desses ideogramas, basta lembrar que letra é a representação de um som que compõe uma palavra, que, por sua vez, transmite uma idéia. O ideograma, embora também represente graficamente um som, não precisa se unir a outros para transmitir idéias: cada ideograma tem um significado. É bem verdade que podem combinar-se ou sobrepor-se uns aos outros a fim de formar idéias mais complexas, o que não prejudica sua autonomia, já que dois ideogramas sobrepostos são, na verdade, um novo ideograma que explicita a relação entre os elementos que o formam, conforme veremos a seguir. 
Quanto à diferença entre ideogramas e palavras, há que se reconhecer que, nas palavras que escrevemos, é máximo o grau de arbitrariedade na relação formasignificado. Já o ideograma chinês lembra a forma daquilo que representa. Como exemplo desta relação, temos abaixo o ideograma para "homem", um desenho de duas pernas:

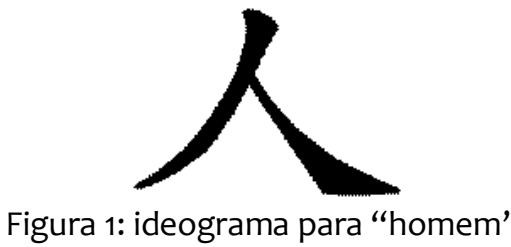

É evidente que, sem prévio conhecimento dos caracteres chineses e de seu funcionamento, seria improvável que alguém ligasse esta figura à idéia de "homem" na primeira tentativa, pois a forma dos caracteres chineses, embora motivada pelo significado, não chega a torná-lo óbvio. Lembramos, ainda, que muitas pesquisas têm se dedicado à tentativa de recuperar ou reconstruir o conhecimento sobre a relação forma-significado de alguns ideogramas, uma vez que a conexão entre alguns caracteres modernos e suas formas primitivas perdeu-se nas inúmeras transcrições realizadas ao longo de milênios.

A sintaxe chinesa também apresenta diferenças relevantes em relação à sintaxe das línguas indo-européias. Embora a distinção entre funções sintáticas no idioma chinês também se dê pela ordem das palavras na sentença, assim como nas línguas neolatinas, no chinês as palavras conectoras - conjunções, preposições etc. - são, na verdade, verbos enfraquecidos. No chinês, predominam substantivos e verbos sobre as outras partes da oração, sendo esta uma das metas da poesia concreta. Daí a afinidade do chinês com as propostas concretistas de abolição da sintaxe lógico-discursiva acompanhada da adoção de uma sintaxe sintético-ideogrâmica.

Esclarecidas as diferenças relevantes para a poesia concreta entre o idioma chinês e os idiomas ocidentais, passemos à análise do "método ideogrâmico de compor", que se baseia em um método de composição de ideogramas que Haroldo de Campos (200ob, p. 47) chama de "evocação por sugestão": usa-se a justaposição de 
dois caracteres para sugerir uma relação entre eles, isto é: “juntam-se dois 'pictogramas' para sugerir uma nova relação, não presente nos meros elementos isolados" (200ob, p. 49). Como exemplo deste processo, temos o ideograma de "sol" unindo-se ao ideograma de "lua" para formar o ideograma de "brilho", como mostram os caracteres abaixo:

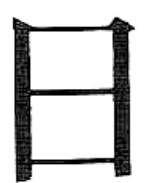

Figura 2: "sol"

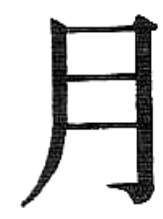

Figura 3: "lua"

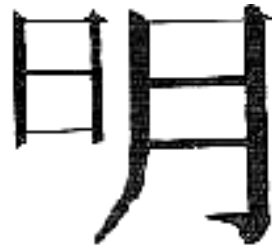

Figura 4: "brilho"

Compor ideogramicamente não significa, assim, apenas inserir ideogramas nos poemas, e sim compor poemas à maneira de ideogramas, isto é, enfatizando o aspecto relacional das palavras, idéias e formas, como acontece acima: sol e lua, objetos brilhantes, unidos, significam brilho, característica comum a ambos e elemento de ligação entre eles. Assim, os ideogramas de "sol” e de "lua" se unem para formar um todo que não é igual à soma de suas partes, mas que evidencia a relação entre elas.

Este método de composição nos remete à teoria da Gestalt, que afirma ser o todo mais que a soma das partes. Para Kurt Koffman,

\footnotetext{
o problema da significação está intimamente ligado ao problema da relação entre o todo e as partes. Já foi dito: o todo é mais que a soma de suas partes. É mais correto dizer-se que o todo é algo diferente da soma de suas partes, já que somar é um processo sem sentido, enquanto que a relação todo-parte é cheia de significado. (apud PIGNATARI, 1975, p. 86)
}

Os resultados da aplicação do método ideogrâmico iriam, portanto, além dos elementos usados na composição. Fica demonstrada, mais uma vez, a conveniência da “descoberta" dos caracteres chineses para a poesia concreta. 
Ezra Pound, poeta americano do século XX, teria sido o pioneiro na aplicação do método ideogrâmico à poesia, utilizando-o no poema épico Cantares ${ }^{1}$, poema extenso e incompleto publicado pela primeira vez em 1922 e conhecido pelo enorme grau de dificuldade que apresenta ao leitor, visto que contém muitas referências a obras clássicas e obscuras. Sobre a estrutura do poema, Haroldo de Campos (1975, p. 96) afirma que

em The Cantos, de E. P., o ideograma é o princípio de estrutura presidindo à interação de blocos de idéias, que se criticam, reiteram e iluminam mutuamente. $O$ isolamento de núcleos temáticos em cadeias de essências e medulas impõe a tomada de consciência do espaço gráfico, como fator de organização do corpo do poema.

Para Hugh Kenner (1985, p. 91-92), o Canto LXXX do poema mostra como o método ideogrâmico dá liberdade ao poeta para mover-se de um assunto a outro sem que a continuidade seja afetada. O poema funcionaria como um conjunto de metáforas construídas através da justaposição e relação entre seus elementos, mesmo que eles não estejam dispostos de forma graficamente contínua.

Assim, a partindo do funcionamento da metáfora, bem como das investidas de Fenollosa contra a lógica aristotélica, presente nos idiomas indo-europeus, Pound adota, em Cantares, os princípios de estrutura do idioma chinês, sem, no entanto, abrir mão completamente da sintaxe discursiva. Os ideogramas presentes no poema indicam relações entre estrofes, o que fica mais evidente à medida que o poema avança. Para Haroldo de Campos (1975, p. 118),

não apenas a compreensão dos Cantos se facilita através do entendimento das potencialidades poéticas do ideograma. (...) Pound, mais do que reviver o chinês, incorpora a estrutura lingüística chinesa, como um valor definido, à problemática da poesia moderna, fazendo atuante a teoria de Ernest Fenollosa.

Haroldo de Campos utiliza método semelhante em "LITAIPOEMA: TRANSA CHIM", um poema de apenas uma página que narra a história de um antigo poeta chinês, chamado Li T'ai Po. Diz a lenda que este poeta morreu afogado aos sessenta e um anos de idade, enquanto tentava, embriagado, abraçar o reflexo da lua nas águas

\footnotetext{
${ }^{1}$ Título original: The Cantos.
} 
de um rio da vila de Tan Tu. Atualmente, é costume os visitantes de seu túmulo deixarem escrito um poema nos muros ou pedras próximos, em homenagem ao poeta.

O “LITAIPOEMA: TRANSA CHIM” contém dez ideogramas cujos significados são semelhantes aos das palavras portuguesas que sucedem, como em:

\section{entre flores 礼 $\mid$ 早}

Figura 5: trecho do "LITAIPOEMA: TRANSA CHIM", de Haroldo de Campos. Fonte: CAMPOS, Haroldo de. Melhores poemas. $3^{\text {a }}$ ed. São Paulo: Global, 2000, p. 112.

Vistos separadamente, o primeiro ideograma significa "entre", e o segundo, "flores". No entanto, combinados, como é o caso, estes dois ideogramas significam "flor desabrochada". Já ideogramas isolados servem, no "LITAIPOEMA...", como instrumento para dar destaque à palavra que sucedem. Ao lermos os ideogramas separadamente em relação ao poema, vemos que formam uma seqüência de imagens mentais que estão relacionadas entre si, à natureza e também ao poema, formando como que uma coluna espinhal do mesmo. Neste poema, assim como nos Cantares, os blocos de idéias se relacionam entre si, regidos pelos ideogramas, que transmitem a idéia principal de cada "área semântica” do poema.

Haroldo de Campos reconhece empregar processos e até mesmo ideogramas semelhantes aos empregados por Pound nos Cantares: “A exemplo de Ezra Pound, nos Cantos, pontuo o texto com alguns dos ideogramas mais relevantes do original assim 'reimaginado'. No final, as próprias reticências contagiam-se dessa ideografia, virando estrelas..." (2000a, p. 150). Além disso, o poema apresenta, conforme as propostas concretistas, estrutura aberta, isto é, não deve ser lido obrigatoriamente da esquerda para a direita e de cima para baixo - o que também acontece em "Um coup de dés", de Mallarmé. De acordo com o eixo e a ordem dos blocos adotada na leitura, podem-se obter novas relações entre os significados das palavras que constituem o poema. 
O mesmo acontece com o poema "via chuang-tsé 1", em que é evidente a ligação entre a estruturação espacial das palavras e o significado das mesmas. As próprias palavras são comparadas a pássaros - ou "pássaros-nomes", que parecem realmente voar pela página. O ideograma de "pássaro" acompanha o poema e torna-se também um "pássaro-nome”.

O título deste poemas faz referência ao filósofo taoísta da China antiga ChuangTsé, cuja filosofia contribuiu para o desenvolvimento de correntes budistas como o Budismo Zen. Chuang-Tsé teria comparado a experiência do estado zen a entrar em uma gaiola de pássaros sem fazê-los cantar. Como em "via chaung-tsé 1" os pássaros são as palavras, a transição para o estado zen significaria a entrada em um mundo onde as palavras não são necessárias.

Longe da pretensão de ter esgotado o assunto, após breve releitura do ensaio "Os caracteres chineses como instrumento para a poesia", esperamos ter exposto de maneira satisfatória o método ideogrâmico de compor adotado pelos concretistas brasileiros, influenciados por Ezra Pound, por sua vez influenciado pelo referido ensaio de Fenollosa. Esperamos, também, ter conseguido demonstrar a maneira como se deu a utilização de ideogramas em dois poemas de Haroldo de Campos.

\section{REFERÊNCIAS}

CAMPOS, Augusto de; CAMPOS, Haroldo de; PIGNATARI, Décio. Teoria da poesia concreta. $2^{a}$ ed. São Paulo: Duas Cidades, 1975.

CAMPOS, Haroldo de. Melhores poemas. $3^{\text {a }}$ ed. São Paulo: Global, 2000.

CAMPOS, Haroldo de (Org.). Ideograma: Lógica - Poesia - Linguagem. Trad. Heloysa Lima Dantas. $4^{a}$ ed. Trad. Heloysa Lima Dantas. São Paulo: Edusp, 2000.

FENOLLOSA, Ernest. "Os caracteres da escrita chinesa como instrumento para a poesia" In: CAMPOS, Haroldo de (Org.). Ideograma: Lógica - Poesia - Linguagem. Trad. Heloysa Lima Dantas. $4^{\text {a }}$ ed. Trad. Heloysa Lima Dantas. São Paulo: Edusp, 2000.

KENNER, Hugh. The poetry of Ezra Pound. London: Faber and Faber, 1985. 
MELO E CASTRO, E. M. de. O fim visual do século XX e outros textos críticos. São Paulo: Edusp, 1993.

OSEKI-DEPRÉ, Inês. "Haroldo de Campos, ou a educação do sexto sentido." In: CAMPOS, Haroldo de. Melhores poemas. $3^{\text {a }}$ ed. São Paulo: Global, 2000.

RAMOS, Maria Luiza. Fenomenologia da obra literária. Rio de Janeiro: Forense, 1972. 